\title{
SOCIOLOGIA E ENGAJAMENTO EM PORTUGAL: reflexões a partir do trabalho e do sindicalismo
}

\author{
Elísio Estanque*
}

\begin{abstract}
O presente paper procura ser um exemplo da sociologia crítica-pública desenvolvida no Centro de Estudos Sociais (CES), da Universidade de Coimbra. A linha temática aqui tratada (sociologia do trabalho e do sindicalismo) assume uma perspectiva crítica, quer do ponto de vista teórico-reflexivo, quer como prática política do cientista social, consideradas duas faces da mesma moeda. Partindo desse ponto de vista, discute-se a atual conjuntura de crise e analisase o caso português à luz da questão do trabalho, realçando alguns dos traços estruturais do país como semiperiferia da Europa e mostrando como alguns dos seus atuais problemas têm origens muito antigas.

PALAVRAS-CHAVE: sociologia pública, crise, trabalho, sindicalismo, Portugal.
\end{abstract}

\begin{abstract}
Pressurgimento relativo da sociedade por tuguesa e os laços de proximidade entre Porugal e o sul global, especialmente com a Africa e a América Latina, herdados da era colonial, criaram um dinamismo raro no nexo entre a sociologia crítica e a sociologia pública, desde os projetos emancipatórios do Forum Social Mundial aos projetos feministas internacionais, passando pelas crí ticas, ao estilo de Bourdieu, à dominação social e à violência simbólica."
\end{abstract}

M. Burawoy, 2007.

A discussão em torno da chamada "public sociology", desencadeada no mundo acadêmico ocidental a partir das contribuições de Michael Burawoy (2005, 2007), colocou-se perante a comunidade sociológica do Centro de Estudos de Sociologia (CES) como uma teorização interessante - porventura capaz de imprimir um sentido mais engajado à sociologia estadunidense, onde pontificou o paradigma funcionalista-, mas com pouca novidade para nós. De fato, há cerca de três décadas que a comunidade sociológica de Coimbra vem se dedicando a produ-

* Doutor em Sociologia. Professor de Sociologia da Universidade de Coimbra. Faculdade de Economia da Universidade de Coimbra - FEUC. Pesquisador do Centro de Estudos Sociais - CES.

Av. Dias da Silva, 165. Cep: 3004-512 Coimbra. Portugal. elisio. estanque@gmail.com zir ciências sociais numa perspectiva crítica, transdisciplinar e assumidamente engajada.

Embora não representativa do CES, que envolve hoje um numero de mais de cem pesquisadores, setenta dos quais com doutorado, a perspectiva crítica e a orientação politicamente engajada dos seus membros é parte integrante da identidade e da tradição desse centro. Nem todos seguem, naturalmente, o mesmo paradigma teórico-epistemológico ou a mesma orientação politica do seu principal líder, Boaventura de Sousa Santos, mas a tendência geral da comunidade do CES é pautada pela preocupação com a interdisciplinaridade, por um lado, e com a intervenção pública e cívica, por outro, e isso não apenas como cidadãos mas também como cientistas sociais.

Procura-se construir um conhecimento progressista, transformador e emancipatório, destinado a reforçar o espaço público. E pretende-se usálo como auxiliar para ver para além do manto de opacidade que as instituições e o poder hegemônico tendem a lançar sobre a realidade, ou, pelo menos, aquela parte da realidade social tendente a pôr em causa as leituras dominantes e a incomo- 
dar a ordem estabelecida. Visualizar o invisível e valorizar, a partir das margens, as múltiplas potencialidades emancipatórias que o centro tem vindo a apagar ou a excluir. Em outras palavras, recusar limitar-se a justificar o que existe só porque existe, e estar atento às ausências e às emergências (Santos, 2000 e 2002a).

O presente artigo tem como objetivo fornecer uma amostra dos temas de estudos que temos desenvolvido, guiados por essa orientação, ou seja, procurando usar a reflexão e a análise sociológica para, a partir dela (e com base nos resultados de diversos estudos em áreas distintas), intervir na esfera pública, procurando dirigir o nosso conhecimento não apenas para as instituições ("policy making"), não apenas para a comunidade acadêmica (numa perspectiva "profissional" ou "crítica”), mas para os públicos subalternos e plurais, no sentido de disseminar informação e conhecimento inovador, capaz de instigar a participação e a cidadania ativa. Dando sequência a um dos princípios orientadores do CES, a filosofia subjacente aos trabalhos realizados nessas áreas - sobretudo a partir do Núcleo de Estudos do Trabalho e Sindicalismo (NETSind) - preocupa-se em contribuir para "democratizar a democracia" ou, por outras palavras, ajudar a reinventá-la, de uma democracia representativa e de baixa intensidade rumo a uma democracia de alta intensidade, em que as dimensões "representativa" e "participativa" se reforcem mutuamente no aprofundamento da cultura democrática (Estanque, 2007; Santos, 1988, 1998, 2000, 2005, 2007).

Pode dizer-se que o desenvolvimento do CES - e de várias das suas linhas de pesquisa numa perspectiva engajada e emancipatória - obedeceu a uma opção estratégica. Aquela que mais diretamente carrega a marca teórica e epistemológica da sua principal referência, Boaventura de Sousa Santos, que vem em estreita continuidade com a primazia das relações de cooperação com os países de língua oficial portuguesa, especialmente o Brasil e as excolônias africanas, que, por essa via, se foi estendendo a toda a América Latina. Em especial a perspectiva epistemológica de crítica frontal ao paradigma ocidental da ciência moderna em favor de uma visão cosmopolita, multiculturalista e emancipatória dos movimentos e dos fenômenos sociais em geral que, nos últimos anos, afirmou-se na defesa da "ecologia dos saberes" e na opção pela "epistemologia do Sul”, não obstante o seu interesse filosófico e o seu potencial crítico sejam assuntos que se apresentam como mais controversos entre os cientistas sociais, inclusive no seio da comunidade do CES (Santos; Menezes, 2009).

Desse modo, a preocupação neste artigo é divulgar junto à comunidade brasileira dos cientistas sociais algumas das leituras e diagnósticos que temos proposto sobre as tendências de mudança no período recente, no campo das relações de trabalho e do sindicalismo. Tais temáticas são, no entanto, perspectivadas no seu sentido mais abrangente, ou seja, como instâncias de eleição em torno das quais qualquer estratégia de modernização, tal como o próprio sistema democrático, tanto se podem consolidar como entrar em colapso. Para além disso, importa referir que - nesse campo como em muitos outros que integram as linhas de pesquisa do $\mathrm{CES}^{1}$ - as notas de reflexão que se seguem são fruto não apenas de resultados de pesquisas diversas, mas, ao mesmo tempo, exprimem o diálogo que temos aprofundado com os atores sociais diretamente intervenientes nesse domínio, quer no âmbito institucional, os que são hoje reconhecidos como "parceiros" de diálogo e concertação social (Estado, sindicatos e empresários), quer os representantes e ativistas que lideram o movimento sindical mais combativo, quer ainda outros líderes associativos do campo estudantil e do trabalho.

A reflexão sobre a questão laboral e social, de uma maneira geral, não poderia, evidentemen-

\footnotetext{
${ }^{1}$ Ver o site do CES em: www.ces.uc.pt. No nosso caso particular, vale a pena referir que, para além desses temas, também a análise das classes e desigualdades sociais (Estanque e Mendes, 1997), do trabalho e do colectivo operário, em articulação com as identidades comunitárias, analisado a partir da observação participante numa empresa de calçados (Estanque, 2000), e os movimentos sociais e estudantis (Estanque e Bebiano, 2007) têm condensado as principais preocupações analíticas e interventivas.(ver: www.ces.uc.pt/investigadores/cv/ elisio_estanque.php)
} 
te, deixar de ser observada sem se levar em conta alguns dos traços específicos da sociedade portuguesa, mostrando as suas vulnerabilidades particulares, que remetem para a história recente do país e para as dificuldades que vem enfrentando na aproximação aos padrões europeus.

\section{DA CRISE E PARA ALÉM DELA: dilemas e dificuldades estruturais}

Numa época de crise internacional que atinge todos os cantos do mundo, é fundamental que nos questionemos sobre os seus impactos, em especial no setor do trabalho, que se assumiu como a infraestrutura fundamental do sistema social e político das sociedades industriais modernas. Começarei por chamar a atenção para dois pontos prévios: em primeiro lugar, existe um conjunto de aspectos relacionados às transformações ocorridas nas últimas décadas, em especial no que tange às grandes mutações socioeconômicas e sua incidência nas relações de trabalho e nos processos produtivos, que devem ser previamente equacionados a fim de se compreender como os impactos da atual crise se fazem sentir de modo muito distinto em diferentes contextos e sociedades particulares; em segundo lugar, é necessário relativizar a tendência para se pensar e discutir todos os assuntos em torno da "crise", como se o mundo tivesse começado em 2008. Tal atitude pode provocar distorções de índole diversa, inclusive perder de vista a complexidade dos fatores estruturais inerentes à sociedade portuguesa, e que definem não só os contornos que a crise assume entre nós, mas também os possíveis caminhos para sair dela e enfrentar um cenário pós-crise. Qualquer diagnóstico que se faça acerca da questão do trabalho - seja ele com respeito ao caso português, brasileiro ou outro -, na difícil conjuntura internacional que hoje vivemos, não pode circunscrever-se à realidade presente (na verdade, apenas o passado se deixa conhecer), devendo antes colocá-la em perspectiva no quadro de um processo histórico mais amplo e de um quadro estrutural mais vasto e profundo.
A noção de "crise" encerra em si mesma uma enorme variedade de significados e, no caso vertente - em que se pensa, sobretudo nas tendências negativas na esfera financeira, econômica e no emprego -, ela recobre todo um leque de realidades bem diferentes, muitas das quais já antigas. Por outro lado, a própria crise econômica foi suscitada por um conjunto complexo de fatores sociais, uns mais estruturais outros mais contingentes. Diversas instâncias políticas e interesses econômicos desencadearam, desde há cerca de trinta anos, um programa de iniciativas que significou uma aposta sem precedentes no comércio livre, na especulação nas bolsas de valores, nas offshores e na economia financeira, fatores que serviriam de barômetro para o crescimento econômico. Os mercados assegurariam um crescimento ilimitado e, portanto, quanto menos regulação e intervenção estatal, tanto melhor. A "bondade" do mercado global parecia garantir o sucesso.

Embora sejam esses alguns dos lemas que conduziram à erupção da atual crise, certos mentores teóricos importantes, como Alan Greenspan, fizeram mea culpa e assumiram o "erro". Com efeito, foram os Estados e as economias mais ricas do mundo, fortemente apoiadas pelos mercados internacionais e pelas novas tecnologias da informação e comunicação, que impuseram, como regra, a abertura total das fronteiras ao comércio mundial, a competitividade deixada ao sabor do mercado etc., envolvendo tudo isso na conhecida retórica neoliberal, que prometia um mundo de oportunidades para os mais competentes e uma "nova economia" capaz de assegurar o bem-estar, senão de todos, pelo menos daqueles - países, economias e indivíduos - que decidissem guiar-se pela aposta nas qualificações, na inovação e na competição. Os resultados desastrosos estão hoje à vista de todos.

\section{GLOBALIZAÇÃO E TRANSFORMAÇÕES NO TRABALHO}

Do mesmo modo que a crise, também a "globalização" tem suscitado muita controvérsia 
justamente devido à sua polissemia. Muito embora se tenha percebido que, afinal, o comércio global é já uma velha história, da qual existem marcas indeléveis há mais de cinco séculos, a reviravolta ocorrida há cerca de três décadas suscitou uma fantástica multiplicação das transações e fluxos de pessoas, bens e serviços de todos os tipos, dando lugar a profundas transformações tanto no plano prático como no plano teórico e conceptual. Com a massificação da indústria turística e a democratização dos transportes aéreos, o mundo ficou menor e passou a ser olhado sob novas perspectivas. As velhas noções de modernidade, desenvolvimento e progresso deram lugar à ideia de pós-modernidade, de imprevisibilidade e de incerteza quanto ao sentido da história e da mudança social. A intensificação das trocas comerciais na escala transnacional, com a ajuda da revolução informática, tecnológica e comunicacional, aceleraram e multiplicaram os processos de mercantilização da vida e das sociedades, ao mesmo tempo em que os Estados e as economias nacionais perderam parte da sua antiga soberania, autonomia e capacidade reguladora.

Porém, ao contrário da retórica liberal e tecnocrática de muitos teóricos e experts, o novo liberalismo que avassalou o mundo desde os anos 1980, não só não atenuou os problemas humanos e os riscos sociais como os agravou drasticamente. É verdade que as oportunidades de negócio e as vantagens lucrativas se mostraram fantásticas para uma ínfima minoria - sobretudo dos que já eram ricos e poderosos -, mas, em contrapartida, a larga maioria das populações e das classes trabalhadoras, incluindo amplos setores da classe média, vêm se debatendo com o agravamento das suas condições de vida e de trabalho. Hoje, muitos constatam a intensificação das desigualdades e injustiças sociais, e mesmo aqueles que mais ativamente glorificaram o mercado livre e as infinitas potencialidades da economia financeira voltam-se agora para o Estado pedindo auxílio.

O campo do trabalho é, sem dúvida, aquele em que os impactos desestruturadores da globalização têm se mostrado mais problemáticos. As consequências disso tornaram-se devastadoras para milhões de trabalhadores de diversos continentes. E o caso particular da Europa é aquele em que as alterações em curso representam um flagrante retrocesso em face das conquistas alcançadas desde o século XIX, com a decisiva contribuição do movimento operário e do sindicalismo. Porque a Europa é justamente a região "referência" e o berço da civilização Ocidental, é necessário pensar em toda a sua tradição humanista e emancipatória, na qual encontraremos a gênese das principais doutrinas progressistas, revoluções e movimentos sociais. O projeto da modernidade e a democracia política assentaram promessas de grande potencial utópico rumo a uma sociedade mais justa e igualitária. Porém, os velhos lemas do iluminismo Liberdade, Igualdade e Fraternidade - foram, nas últimas décadas, secundarizados, se não mesmo desprezados ostensivamente, no discurso institucional de governantes e dirigentes (inclusive de correntes como a social-democracia, cuja história e referências éticas e doutrinárias se inscrevem em projetos e ideologias desse teor). Os efeitos da globalização induziram novas formas de trabalho cada vez mais desreguladas, num quadro social marcado pela flexibilidade, subcontratação, desemprego, individualização e precariedade do trabalho. Assistiu-se a uma progressiva redução de direitos trabalhistas e sociais, e ao aumento da insegurança e do risco, num processo que se revelou devastador para a classe trabalhadora e o sindicalismo os finais do século XX (Castells, 1999; Beck, 2000; Estanque, 2007).

A realidade do mundo do trabalho, nos últimos tempos, atualizou visões críticas do capitalismo até há pouco julgadas ultrapassadas. Karl Marx e a sua obra maior, OCapital, voltou a suscitar as atenções do mundo, quer por parte de acadêmicos, quer por parte da opinião pública em geral. Mas, se o pensamento marxista parece ganhar nova atualidade, não é porque se pretenda recuperar a ortodoxia leninista ou reincidir em modelos comprovadamente falidos, como o soviético. É sim porque o mercado desregulado, a intensificação da exploração - sob velhas ou novas formas - e todo o conjunto de problemas socioeconômicos que a atual crise 
aprofundou (em muitos casos pondo a nu o que já lá estava, mas ainda imperceptível) comprovaram a falência do paradigma neoliberal e requerem, por isso, que se repensem os modelos de mercado que guiaram a economia mundial nos últimos tempos.

Em especial no campo do emprego, temos assistido a um efeito de pêndulo, em que cada vez menos trabalhadores se encontram numa situação de emprego seguro, estável e com direitos, enquanto existem cada vez mais pessoas desempregadas que se debatem com o iminente risco de pobreza e exclusão. Como os vagabundos do século XVIII europeu ou os chamados malteses alentejanos de meados do século XX, essa gente vê negados os direitos mais elementares. São atirados ao mundo em uma busca desesperada de subsistência e obrigados a aceitar quaisquer condições de trabalho e a se entregarem à vontade gananciosa de patrões sem escrúpulos. Excluídos, de fato, do estatuto de cidadania, são por vezes eles próprios que se negam a si mesmos o direito de procurar um trabalho digno, aceitando ser tratados como sub-humanos ou como os novos escravos da economia global do século XXI.

Os processos recentes de fragmentação e precarização das relações e formas de trabalho atingiram o conjunto das classes trabalhadoras e pulverizaram as próprias estruturas contratuais e organizacionais do sistema produtivo. Perante o triunfo do neoliberalismo econômico e o acentuar de novas formas de opressão e exploração, alguns dos velhos conceitos e dicotomias de Marx - tais como as divisões entre capital fixo e capital circulante; trabalho vivo e trabalho morto; trabalho material e trabalho imaterial; atividades produtivas e improdutivas - são hoje reconceitualizados à luz da nova dinâmica do capitalismo global. As atuais tendências permitem mostrar como aquelas divisões foram reconvertidas e se imbricam hoje dialeticamente umas nas outras, contribuindo, assim, para intensificar e expandir novas formas de "estranhamento" e "alienação" das classes trabalhadoras e dos novos segmentos precarizados. Porém o trabalho, em vez de desaparecer e se diluir para dar lugar ao lazer e ao consumo, ganha nova centralidade, ao mesmo tempo que se combina sob diferentes lógicas e formas mais instáveis (metamorfoseia-se) e, em muitos casos, mais penosas para quem tem de viver de qualquer trabalho. Tornou-se clara a versatilidade, a instabilidade e a multiplicidade de formas e de sentidos que envolvem o trabalho e seus mundos no início do século XXI. Muito embora se tenha esbatido como potência criadora e espaço de consolidação de "subjetividades de classe" dirigidas para a ação transformadora, o trabalho, material e imaterial permanece como o módulo central no processo de acumulação capitalista (Antunes, 2006).

O flagelo do desemprego, associado a um “individualismo negativo" (Castel, 1998), que se assemelha a fenômenos que ocorreram na Europa do século XVIII, resultante dessa precariedade geradora das mais diversas formas de dependência, insegurança, resignação e medo - permite todo o tipo de prepotências e abusos. No atual panorama, já não são os direitos trabalhistas aquilo que se pretende defender, mas, do ponto de vista de milhões de assalariados, tão só o emprego a todo o custo, pois "o pior dos empregos é sempre preferível ao desemprego" - o que traduz bem a debilidade em que se encontra hoje o trabalhador. Desmantelou-se o velho compromisso entre capital e trabalho, e a concertação social - a negociação "tripartite" -, essa velha conquista do fordismo e do Estado de Bem-Estar europeu, tornou-se uma mera figura de retórica em que já nem as forças políticas herdeiras da social-democracia parecem acreditar, sobretudo quando alcançam o poder.

\section{A SOCIEDADE PORTUGUESA NO CONTEXTO EUROPEU}

A esse respeito convém apresentar alguns traços particulares da sociedade portuguesa. Portugal é, como todos reconhecemos, um país periférico da Europa, cujas dificuldades se devem a um tardio e incipiente desenvolvimento industrial, bem como a um processo de democratização igualmente recente e repleto de contradições. Com 
a instauração da democracia em 1974, consolidaram-se as classes trabalhadoras vinculadas à industria, além dos setores da nova classe média assalariada (setor administrativo, saúde, educação, poder local e funcionalismo público em geral) que rapidamente se expandiram - apesar de, no seu conjunto, a classe média portuguesa ter permanecido débil - sob o impulso de um Estado de BemEstar Social em rápido crescimento, apesar de ele próprio ser fraco. Aliás, convém lembrar que Portugal começou a construir o seu Estado social numa altura em que já estavam a emergir os sinais de crise desse modelo na Europa, ou seja, tentou-se alcançar o comboio quando ele já chegava ao fim da viagem.

Daí que as transformações sociais desencadeadas com o 25 de Abril de 1974 - e, de certo modo, consignado na constituição "socialista" de 1976 -, sendo, sem dúvida, profundas em muitos aspectos, nunca deixaram de evidenciar os contrastes que persistiam e persistem na sociedade portuguesa. A modernização das infraestruturas, em especial após a adesão à União Europeia, em 1986, trouxe progressos inquestionáveis, mas, no plano social, as dificuldades, injustiças e bloqueios persistiram. Muito embora os trabalhadores e as classes subalternas em geral tenham melhorado substancialmente as suas condições de vida, em comparação com a miséria em que viviam há 30 ou 40 anos, o certo é que as elites - em especial as novas elites privilegiadas, ligadas à indústria e ao comércio - ascenderam muito rapidamente, distanciando-se dos níveis de vida da classe média e dos trabalhadores manuais. A “classe média” cresceu até finais do século, em boa medida à sombra do crescimento do Estado, como se disse, mas, ao mesmo tempo, permaneceu instável e internamente muito diferenciada.

Pode até dizer-se que a classe média portuguesa foi mais importante pelo seu papel como referência simbólica no imaginário coletivo do que por ser um segmento social consistente e dotado de índices elevados de bem-estar. Foi, sobretudo, o resultado de uma rápida concentração urbana e da facilitação do crédito, aspectos decisivos para que esses setores recém-urbanizados começassem a estruturar padrões de vida subjetivamente projetados numa imaginária “classe média”, ou, em outras palavras, numa categoria supostamente “distintiva” e "superior”, por comparação com os grupos de referência originários, isto é, os que remetiam para um mundo rural e pobre, que se pretendia ver ultrapassado. Assim, como alguns estudos mostraram (Estanque, 2003; Cabral, 2003), uma parte significativa da própria classe trabalhadora manual, incluindo alguns dos seus segmentos mais precarizados, percebia-se como pertencendo à "classe média”.

Ora, se o consumismo desenfreado e as expectativas de mobilidade ascendente puderam alimentar tais ilusões durante algum tempo, com a entrada no novo milênio e, sobretudo, perante o reforço da competitividade global, a contenção de custos e as pressões para a flexibilização e privatização (mesmo nos setores onde o emprego se mantinha relativamente seguro) deram início a uma profunda mudança na esfera do emprego, evidenciando, assim, uma vez mais, o caráter persistente e estrutural das nossas debilidades. Problemas supostamente resolvidos há décadas ressurgiram, tais como a pobreza, a falta de qualificação de trabalhadores e empresários, as elevadas taxas de evasão escolar, o crescimento brutal das desigualdades sociais, o aumento do desemprego e da pobreza, as desigualdades de gênero e uma rápida precarização do trabalho, que atingiu em especial os setores mais jovens (incluindo os mais escolarizados).

Temos, portanto, sobre os nossos ombros, um passado recente marcado por inúmeros contrastes, e é neles que porventura repousam as causas mais decisivas do nosso atraso estrutural. A cultura tradicional do país e a escassa qualificação dos agentes econômicos (empresários e trabalhadores) espelham ainda os atributos de uma sociedade subdesenvolvida, amarrada às mentalidades atávicas e paroquiais, aqui e ali deixando ainda transparecer alguns resquícios de feudalismo e de salazarismo. Prevalecem os modelos de gestão de natureza despótica, lado a lado com dependênci- 
as e tutelas de todos os tipos, que se adaptam de modo perverso à vida moderna, corroendo o funcionamento das empresas e instituições e travando as potencialidades de modernização econômica e de aprofundamento democrático.

Mantêm-se ou intensificam-se os velhos dualismos, tais como a divisão entre o interior e o litoral ou entre o rural e o urbano, muito embora tais divisões conservem fortes imbricações recíprocas. Essas antigas contradições continuam a persistir, embora se adaptem aos tempos atuais. Os setores protegidos do emprego tornam-se cada vez mais raros, enquanto o emprego precário subiu acima dos 20\% (22\% em 2007 para os trabalhadores com menos de 35 anos) e, nas camadas mais jovens, atinge cerca do dobro desse percentual, o que, por sua vez, exprime a contradição geracional entre uma juventude mais qualificada, mas também mais precária, e as condições de trabalho dos seus pais ou avós. O discurso da privatização foi, durante décadas, elevado ao estatuto de único legítimo, pois apoiado na competitividade, e, ao abrigo desse discurso - erigido em pensamento único por parte do poder-, desencadearam-se diversas reformas nos serviços públicos em diversas áreas, tais como a saúde, o funcionalismo público, a educação e outras, justificando-se tais mudanças com base num suposto privilégio dos trabalhadores e funcionários da administração pública, por contraste com os do setor privado, servindo esse argumento para uma clara estratégia de nivelamento por baixo.

Porém, quer a capacidade de realizar as reformas, quer as possibilidades de lhes resistir, bem como a razoabilidade com que as mesmas são concebidas e levadas à cabo são parte de processos mais complexos que só poderemos interpretar se forem situados no devido contexto e na própria historia. Eéjustamente a essa luz que as propostas legislativas de alteração do sistema de relações laborais, para terem sucesso, deveriam começar por diagnosticar a realidade que temos, não com base em juízos ideológicos, mas tendo presente o contexto onde nos inserimos e o património sociocultural que herdamos do passado. Sem considerarmos a his- tória e o significado das lutas sociais dos trabalhadores europeus ao longo dos últimos cento e cinquenta ou duzentos anos, jamais compreenderemos a diferença entre o modelo social europeu e o mercantilismo individualista dos países anglosaxônicos. Se houve efetivamente progressos fundamentais na Europa ao longo de todo esse tempo, eles se devem essencialmente à capacidade de organização e de luta coletiva da classe trabalhadora e do movimento operário nos países industrializados. Esse é, de resto, um patrimônio que é reivindicado por toda a esquerda, desde a social-democracia até o movimento comunista.

Se hoje temos mecanismos de regulação dos conflitos e uma ordem jurídica que privilegia o diálogo e a concertação entre os diferentes parceiros e classes sociais, isso se deve aos grandes sacrifícios e às lutas do movimento operário. Nesse sentido, o direito do trabalho foi (e é) um instrumento decisivo a serviço dos trabalhadores, destinado a reequilibrar as relações sociais entre capital e trabalho, que são, como se sabe, estruturalmente assimétricas. No entanto, apesar dos avanços alcançados, em muitos países persistiram, ao longo dos tempos, inúmeras formas de trabalho fora de qualquer proteção jurídica, e a erosão dos direitos sociais e econômicos dos trabalhadores suplantou largamente a força da lei. Como sabemos, isso ainda ocorre em diversas regióes do globo.

Sendo expressão das relações políticas numa sociedade, a ordem jurídica funcionou, ao longo da história, como meio de legitimação de relações de poder fortemente desequilibradas, impondo-se geralmente sobre uma força de trabalho submissa e destituída dos direitos mais elementares, sem um salário digno ou proteção social e sem acesso aos direitos humanos mais elementares. No entanto, a transformação histórica obteve importantes resultados de sentido emancipatório, em particular nos países mais avançados. O direito do trabalho triunfou nos países europeus e é uma bandeira fundamental para trabalhadores dos mais diversos continentes, justamente porque representa uma poderosa arma a serviço das classes subalternas, defendida, desde sempre, pelo movimento 
sindical internacional e veiculada por organizações internacionais como a OIT, que tem prestado um inestimável papel na defesa dos direitos humanos no trabalho, em todos os continentes. É precisamente à luz desse patrimônio histórico, de que a Europa é um palco privilegiado, que as mudanças impostas pelos poderes dominantes nessa matéria - no sentido de uma flexibilidade ditada pela concorrência desregrada, pelos requisitos do mercado global e pelas exigências do grande capital - correm o risco de representar uma regressão inaceitável para os trabalhadores europeus.

Portugal, com todas as suas especificidades, insere-se justamente nesse quadro. E é por isso que as alterações que o novo Código do Trabalho 2 vem introduzir são, em variadas matérias (ou melhor, nos seus aspectos mais decisivos), motivo de grande apreensão para aqueles que assumem a defesa da classe trabalhadora contra a exploração capitalista (cerca de cento e quarenta anos após a $1^{\text {a }}$ edição do livro 1 de $O$ Capital) e contra outras formas de opressão e de injustiça social. Acresce que as condições de subdesenvolvimento já referidas colocam a sociedade portuguesa - e a sua força de trabalho assalariada - numa situação de especial vulnerabilidade, visto que estamos longe de garantir plenamente os direitos de cidadania. Como muitos de nós temos apontado repetidamente, existem medos incrustados nas instituições, que impedem o fortalecimento da esfera pública e tendem a inibir qualquer ação reivindicativa no campo profissional, onde imperam os constrangimentos e a mentalidade autoritária de empresários e chefias. A presença de culturas autocráticas, de tutelas e compadrios dos mais diversos tipos, onde deveriam prevalecer a transparência, as estratégias de gestão e lideranças democráticas, são ingredientes que

2 Designação atribuída ao pacote legislativo na área trabalhista, que teve uma primeira versão em 2003, no governo do PSD, dirigido por Durão Barroso, e que mais recentemente foi reformulado e aprovado pela Assembleia da República, em 2008. A nova orientação, defendida pelo PS de José Sócrates, teve, porém, uma forte oposição, sobretudo por parte dos partidos à sua esquerda (o Partido Comunista e o Bloco de Esquerda) e também po parte do campo sindical (em especial a central sindical mais representativa e combativa, a CGTP), que mobilizou, em 2008, várias manifestações de rua em Lisboa algumas delas com mais de duzentos mil participantes. corroem as nossas instituições, desestimulando o trabalhador dedicado. Em vez do mérito e da iniciativa individual, prevalecem as posturas e atitudes de bajulação e resignação perante a autoridade; em vez do ambiente de exigência e de estímulo à criatividade e à co-responsabilização (individual e coletiva), cultiva-se o "seguidismo" e a mediocridade; em vez de cidadãos livres e autônomos, promove-se o oportunismo e a delação. Tudo isso é o contrário de uma sociedade democrática avançada. Tudo isso se opõe aos valores do socialismo democrático. E a tudo isso é possível fazer frente. A questão está em saber se os governos e a classe dirigente pretendem inverter esse rumo ou contribuir para que ele se torne irreversível e nos empurre de novo para o abismo.

Ora, perante esse panorama - e como diversos estudos internacionais têm mostrado-, a questão da estabilidade e da segurança no emprego constitui o principal motivo de preocupação dos trabalhadores. Encontrar um primeiro emprego é a primeira das prioridades dos estudantes do ensino superior (Estanque; Bebiano, 2007).

Hoje, se é "jovem" até muito além dos 30 , porque muito ficam dependentes da família até muito tarde, mas se é por vezes considerado "velho" quando, trabalhadores desempregados, com quarenta e poucos anos, são preteridos devido à idade. A perda do emprego é a principal ansiedade frente à qual muitas outras exigências, mesmos as mais evidentes, podem ser sacrificadas. Existem empresas, nos EUA e na Europa, que estabelecem um salário máximo, pedindo aos candidatos a um posto de trabalho que indiquem quanto "pretendem" ganhar, até esse nível máximo (por exemplo, oito euros por hora), o que induz a um constante rebaixamento salarial indicado pelos pretendentes ao emprego (os que indicam quatro euros ou menos serão naturalmente os preferidos). É a lógica da autonegação da dignidade, produzida pelo espectro do desemprego e da miséria. O clima de angústia que o atual cenário de crise tem acentuado só contribui para que tais sintomas "patológicos" se tornem ainda mais dramáticos do que até agora temos conhecido. 
Porém, quando o trabalhador (ou o cidadão) é sistematicamente reprimido e impedido de manifestar a sua vontade ou de exigir o cumprimento de direitos, o que acontece é o aumento do descontentamento e da contrariedade no trabalho e na sociedade. Daí resulta, então, uma de duas posições: ou se acentua a resignação e o medo, ou aumenta a crispação e o sentimento de revolta. Esse ambiente-agravado com as múltiplas formas de recomposição, desmembramento, flexibilidade, deslocalização e fechamento de empresas, precarização do trabalho, fragmentação dos processos produtivos etc. - tem conduzido a classe trabalhadora a uma cultura de impotência e de conformismo. Uma "classe" cada vez mais heterogênea e frágil, que se depara com tremendas dificuldades em agir coletivamente. Há muito que as identidades de classe perderam fulgor em favor de outras identidades rivais e de outras formas de ação coletiva (e de inação), num processo que se acentuou enormemente com o colapso do regime soviético e, no caso português, após a saturação da linguagem marxista e "de classe" de que se usou e abusou no período da Revolução dos Cravos (1974). Perante o refluxo da ação coletiva e do discurso ideológico, os sindicatos perderam força e capacidade de organização e de mobilização, nomeadamente junto dos segmentos mais fragilizados e mais jovens da força de trabalho. Para além de um contexto social e político pouco favorável à participação coletiva e associativa - e sem esquecer as próprias dificuldades de renovação do sindicalismo (Estanque, 2008) -, o reforço do poder patronal e a retirada de condições favoráveis à ação sindical vêm agravar ainda mais essas tendências.

\section{SINDICALISMO E AÇÃO COLETIVA, ANTESE APÓS A CRISE}

Nessa discussão, torna-se incontornável equacionar a questão sindical. Se nos despirmos de juízos de valor e, sobretudo, se formos capazes de evitar a tendência de classificar os sindicatos entres os "bons" e os "maus" (uns com quem, su- postamente, se pode dialogar e os outros, ditos conservadores ou "ao serviço de...”), seremos levados a perceber o papel social e transformador do sindicalismo (e tanto a contestação como a negociação são vias igualmente válidas no plano social) e talvez então se possa aceitar que o sindicalismo combativo e de movimento é aquele que maior contribuição deu e pode dar ao progresso social.

É sobretudo em períodos de crise e de dificuldades para as classes trabalhadoras que ocorrem as grandes reviravoltas históricas, normalmente acompanhadas de novos movimentos e da emergência de novas lideranças. Na Inglaterra do século XIX e noutros contextos históricos mais recentes - de que pode ser exemplo o 25 de abril de 1974 -, a mobilização popular não se deveu apenas a motivações políticas e econômicas (nem a causas racionais, da ordem da "consciência" ou dos “interesses”), mas também, talvez, sobretudo, a fatores culturais e identitários. A identidade precede os interesses. Mas estes, quando fundados em fortes carências e necessidades básicas por satisfazer, podem produzir rebeliões radicais e de massas, ainda que não sejam orientadas por nenhuma motivação política explícita (ou inspiradas numa ideologia identificável).

A classe trabalhadora deixou há muito de ser homogênea (porventura nunca chegou a sê-lo, a não ser em contextos muito particulares), mas a difusão da precarização e do trabalho sem estatuto e sem dignidade pode conduzir a novas homogeneizações, que, embora de base trans-classista, sejam capazes de se unificar na defesa de uma identidade agredida e ofendida nos locais de trabalho, mas também na comunidade de residência ou na relação com os serviços públicos. Mesmo a participação, a solidariedade e a partilha coletiva da indignação podem recuperar um certo sentido de recompensa simbólica, estimulando o desejo de reconstrução comunitária, quer se esteja voltado para um passado nostálgico e em nome das "raízes" (por exemplo, o nacionalismo ou o bairrismo), quer se projete num futuro promissor e "emancipatório" como, por exemplo, o socialismo (Tilly, 1978; Morris, 1996; Estanque, 2000). 
Tomados por muitos como fatores de bloqueio ao crescimento econômico e ao desenvolvimento, os sindicatos queixam-se, com razão, de que, em diversas regiões do mundo, as formas de trabalho parecem ter regressado aos tempos "satânicos” de Marx. Mas, apesar da mítica classe operária estar em desagregação, não surge no horizonte nenhuma outra identidade capaz de congregar a unidade dos assalariados. As atuais pressões do mercado e da economia global deixam aos sindicatos uma margem de manobra cada vez mais estreita, mas, por outro lado, o esforço de atualização por parte das estruturas sindicais tem sido diminuto e insuficiente para responder aos problemas da atualidade. Sobra, então, espaço para novos atores e movimentos.

Nas últimas décadas, enquanto a economia e os mercados deixaram de estar confinados às fronteiras nacionais, o movimento sindical revelou enormes dificuldades em agir para além do âmbito nacional (e, muitas vezes, do próprio âmbito setorial). A globalização revelou-se contraditória e gerou múltiplos efeitos paradoxais, nomeadamente ondas sucessivas de protestos juvenis e movimentos sociais que se reclamaram de "alterglobalização”. Desde a cúpula da Organização Mundial do Comércio (OMC) em Seattle, em 1999, passando pelos encontros do Fórum Social Mundial, em Porto Alegre e outras cidades, esse ativismo - largamente apoiado pelas redes virtuais do ciberespaço - revelou novas e inovadoras formas de denúncia e de intervenção pública, que até agora têm marcado as formas de ativismo global do século XXI. As mais recentes ondas de contestação dos jovens (França, Grécia, Catalunha), invocam, por vezes, o Maio de 68, até porque as condições sociais são igualmente ativadas por condições semelhantes, em que os grupos e as comunidades de jovens se afirmam, mobilizando-se contra um opositor, ou um "inimigo" identificado. Mas são fenômenos muito distintos. Enquanto, naquela época, era a consciência política e as autoproclamadas "vanguardas" que assumiam a liderança da luta, agora a ação coletiva perdeu parte do seu conteúdo político. Dito de outro modo, continua em vi- gor o princípio da "válvula de escape", mas os seus efeitos são politicamente incertos. As ondas de protesto e o discurso de indignação que as acompanha, exacerbados por um poder (institucional, empresarial ou governamental) de viés autoritário, podem ganhar um efeito mimético de proporções imprevisíveis, se para tal as condições sociais se tornarem propícias.

O atual contexto de crise, ao mesmo tempo em que ameaça desfazer um conjunto de laços sociais que até aqui garantiam a coesão mínima da sociedade, pode - precisamente porque o sistema social tem horror ao vazio - galvanizar de novo as multidões que se sentem ressentidas e desprotegidas. $\mathrm{E}$ o fato de o sindicalismo apenas timidamente se envolver nesse tipo de iniciativas, até agora, não garante que elas continuem a ter uma expressão modesta. Até porque, se o presente é fortemente marcado pela contingência, tanto pode acontecer que expressões de grupos minoritários (sejam eles os MayDay, os FERVE ou outros ${ }^{3}$ ) possam repentinamente se alastrar, como a própria intensificação da pressão pode levar a que o sindicalismo radicalize o seu discurso e consiga mobilizar a massa de precários e desempregados que tem vindo a engrossar e ameaça expandir-se ao longo de 2009.

Diversos autores e acadêmicos têm formulado a necessidade de se criarem novas alianças e

MayDay: um movimento autônomo ativado por grupos de trabalhadores precários em vários países europeus, com influência da extrema-esquerda, que há cerca de três anos se estendeu a Portugal e começou a organizar manifestações no dia 1 de maio. Já o FERVE - Fartos d' Estes Recibos Verdes - é uma organização ou movimento que surgiu de forma espontânea a partir de um grupo de jovens trabalhadores, com contratos precários, cujo estatuto de prestações e registo fiscal é feito com base nos "Recibos Verdes", ou seja, um livro de recibos fornecido pela repartição de finanças para trabalhadores autônomos ou profissionais liberais (como advogados, técnicos de contas, canalizadores etc). O regime de recibo verde foi concebido para trabalhos pontuais, mas em Portugal, como até recentemente, a legislação trabalhista era considerada muito rígida (na proteção ao trabalhador e, sobretudo, na prevenção da demissão ilegal) e começou a generalizar-se nas empresas o recurso a esse tipo de prestação, desde os anos 90, como forma de contornar o direito do trabalho e facilitar as demissões. Daí surgiram os chamados "falsos recibos verdes”, isto é, situações em que o mesmo trabalhador permanecia com esse estatuto precário (e poupando os encargos às empresas) durante anos, contribuindo para aumentar, juntamente com os contratos a prazo, o volume de assalariados nessa situação (que se situa hoje entre 18 a $20 \%$ da força de trabalho, mas bem acima disso nas camadas mais jovens). 
dinâmicas internacionalistas, como condição para revitalizar o sindicalismo perante o agravamento das desigualdades e injustiças sociais em todos os continentes, alegando que a mobilidade global de capitais e de empresas funcionando em redeexige respostas sindicais também em rede e igualmente articuladas na escala transnacional (Waterman, 2002; Estanque, 2007). Ao contrário de outros países e regiões, como o Brasil e a América Latina, onde a cooperação entre as universidades, os acadêmicos e os centros de pesquisa, de um lado, e os movimentos sociais e sindicais, de outro, são uma constante, em Portugal essa tradição praticamente não existe.

As novas redes e estruturas transnacionais de organização política são cada vez mais necessárias. Não apenas na União Europeia, onde as famílias políticas possuem ainda pouca eficácia e os próprias estruturas sindicais são incipientes. Para enfrentar os atuais desafios (que a crise apenas veio acelerar), o sindicalismo de hoje terá de se reinventar ou se reestruturar profundamente. Um sindicalismo de movimento social global, orientado para a intervenção cidadã, terá de se estender para além da esfera laboral; terá de passar das solidariedades nacionais para as transnacionais, de dentro para fora, dos países avançados para os países pobres. Precisamos de um sindicalismo que não abdique da defesa dos valores democráticos, mas em que eles se alarguem à democracia participativa (nas empresas, escolas, cidades, comunidades etc.); que coloque as questões ambientais e a defesa dos consumidores, dos saberes e tradições culturais locais no centro das suas lutas e negociações; que resista ao capitalismo destrutivo através de um maior controle sobre o processo produtivo, os investimentos, a inovação tecnológica e as políticas de formação e qualificação profissional; que pense os problemas laborais no quadro mais vasto da sociedade, da cultura ao consumo, do trabalho ao lazer, da empresa à família, do local ao global (Estanque, 2004; Hyman, 2002).

Mas tudo isso pressupõe uma estratégia ambiciosa que rompa com a prática de acomodação ao funcionamento burocrático em que boa par- te do sindicalismo de hoje se deixou enredar. Exige uma reflexão séria e uma atitude autocrítica e porventura mais humilde da parte das atuais lideranças sindicais, associativas e institucionais, em todos os domínios da nossa vida social.

Por exemplo, a extraordinária capacidade da internet e do ciberespaço constitui um enorme potencial ainda subaproveitado. A facilidade para aceder à informação, para acumular e divulgar conhecimento em frações de segundo poderia ser uma poderosa arma a serviço do movimento sindical e da democracia em geral (Ribeiro, 2000; Waterman, 2002). O problema não reside, portanto, na tecnologia ou na sua ausência. O problema é que os atributos socioculturais que enunciei anteriormente se refletem e se reproduzem nos mais diversos meios e instâncias organizacionais, inibindo, assim, uma maior transparência na gestão das instituições e travando, sem sabermos até onde, o processo de consolidação e aprofundamento democrático.

\section{CONCLUSÃO}

Concluindo, a crise que nos surpreendeu no final de 2008 tem causas bem mais profundas e longínquas do que pode parecer. E o modo como setores decisivos, como o do emprego, são ou não capazes de responder às dificuldades e problemas do presente deriva, em boa medida, da capacidade que tenha de reconverter algumas das velhas pechas do nosso sistema produtivo em potencialidades de mudança. Mudança para um outro paradigma. E isso depende muito dos agentes econômicos em posições de liderança e da capacidade do próprio poder político de aceitar o surgimento de novos protagonistas e de novas posturas com sentido ético, animados pela defesa da causa pública, em busca do bem-estar geral e da construção de vínculos de solidariedade com as classes subalternas.

Essa visão resulta, como indicamos no início deste artigo, de um conjunto de atividades, de pesquisa e de intervenção, que temos desenvolvido no CES há cerca de 20 anos. A preocupação em levar a sociologia para fora dos muros da uni- 
versidade não é nova para nós. E, no campo concreto do sindicalismo e do trabalho, talvez não seja um mero acaso que as pessoas que integram a equipe e o núcleo de pesquisa (NETSind) quase todas elas tiveram experiências profissionais marcantes desde muito jovens e ao longo do seu percurso de vida. Por outro lado, participaram ou militaram em sindicatos, partidos ou movimentos sociais e associativos progressistas.

De resto, quer o trabalho de observação participante durante três meses numa fábrica de calçados, trabalhando oito horas diárias na linha de montagem e convivendo diáriamente com os operários, dentro e fora da empresa, quer os estudos sobre o movimento estudantil e o envolvimento com os estudantes nas comunidades das "repúblicas" estudantis de Coimbra (Estanque, 2008a), mas também o engajamento em associações de defesa da cidade (no caso a PRO URBE) e a própria militância partidária (no caso o Partido Socialista e os movimentos dirigidos pelo ex-candidato presidencial e poeta das canções de Coimbra, Manuel Alegre) são todos eles domínios de intervenção onde a sociologia se conjuga estreitamente com o ativismo social e político.

Se é verdade que a ciência social deve procurar a objetividade e ser teórica e metodologicamente rigorosa - sem se deixar confundir com a ideologia e, menos ainda, com a ortodoxia -, também é necessário não esquecer que, entre a realidade e a imaginação sociológica, não há qualquer incompatibilidade. Antes pelo contrário: as zonas ocultas da primeira só podem ser iluminadas com o auxílio da segunda. E saber de que lado estamos nesse mundo de contrastes e de injustiças é uma opção que não pode ser ditada por critérios científicos, mas pelos valores e princípios éticos que guiam o cientista social nas suas escolhas e na sua ação (como cientista e como cidadão).

(Recebido para publicação em abril de 2009) (Aceito em julho de 2009)

\section{REFERÊNCIAS}

ANTUNES, Ricardo (Org.). Riqueza e miséria do trabalho no Brasil. São Paulo: Editora Boitempo, 2006.

BECK, Ulrich. Un nuevo mundo feliz: la precaridad del trabajo en la era de la globalización. Barcelona: Paidós, 2000. BURAWOY, Michael . For public sociology. American Journal Review, v. 70, p. 4-28, february, 2005.

Open Social Sciences: to whom, for what? Portuguese Journal of Social Science, v. 6, n. 3, 2007.

CABRAL, M. Villaverde, et al (Orgs.). Desigualdades sociais e percepções da justiça. Lisboa: ICS, 2003.

CASTEL, Robert. As metamorfoses da questão social. Petrópolis: Editora Vozes, 1998

CASTELLS, Manuel. A sociedade em Rede - A era da informação: economia, sociedade e cultura, São Paulo: Paz e Terra, 1999.

ESTANQUE, Elísio. Entre a fábrica e a comunidade: subjectividades e práticas de classe no operariado do calçado. Porto: Afrontamento, 2000.

O efeito classe média - desigualdades e oportunidades no limiar do século XXI. In: CABRAL, M. V., J. Vala e A. Freire (Orgs.). Percepções e avaliações das desigualdades e da justiça em Portugal numa perspectiva comparada. Lisboa: ICS, 2003.

A Reinvenção do sindicalismo e os novos desafios emancipatórios: do despotismo local à mobilização global. In: SANTOS, Boaventura S. (Org.). Trabalhar o mundo: os caminhos do novo internacionalismo operário. Porto: Afrontamento, p. 297-334, 2004.

A questão social e a democracia no início do século XXI: participação cívica, desigualdades sociais e sindicalismo, Finisterra - Revista de Reflexão Crítica, Lisboa, v. 55/56/57, p. 77-99, 2007.

Sindicalismo e movimentos sociais: dilemas e perplexidades e Entre os velhos e os novos activismos: tensões e desafios do movimento sindical. Revista JANUS - Anuário de Relações Internacionais, v. 20. Lisboa, UAL/ Jornal Público, p. 184-187, 2008.

Jovens, estudantes e 'repúblicos': culturas estudantis e crise do associativismo em Coimbra, Revista Crítica de Ciências Sociais, n. 81, p. 9-41, 2008a.

; MENDES, José Manuel. Classes e desigualdades sociais em Portugal: um estudo comparativo. Porto: Afrontamento, 1997.

- BEBIANO, Rui. Do activismo à indiferença: movimentos estudantis em Coimbra. Lisboa: ICS, 2007.

HYMAN, Richard. Europeização ou erosão das relações laborais?. Revista Crítica de Ciências Sociais, n. 62 Coimbra: CES, p. 7-32, 2002.

MORRIS, Paul. Community beyond tradition. In: HEELAS, Paul et al. (Eds.), Detraditionalization. Oxford: Blackwell, 223-249, 1996.

RIBEIRO, Gustavo Lins. Política cibercultural: ativismo político à distância na comunidade transnacional imaginadavirtual. In: ALVEREZ, S.; DAGNINO, E.; A. Escobar (Orgs.) Cultura e política nos movimentos sociais latino-americanos. Belo Horizonte: Editora UFMG, p. 465-502, 2000.

SANTOS, Boaventura de Sousa. Um Discurso sobre as Ciências. Porto: Afrontamento, 1988.

. Reinventar a democracia. Lisboa: Gradiva, 1998.

. A Crítica da razão indolente: contra o desperdício da experiência. Porto: Afrontamento, 2000. 
(Org.) Democratizar a democracia: os caminhos da democracia participativa. Rio de Janeiro: Civilização Brasileira, 2002.

Para uma sociologia das ausências e uma sociologia das emergências. Revista Crítica de Ciências Sociais, n. 62, p. 237-280, 2002a.

(Org.) Trabalhar o mundo: os caminhos do novo internacionalismo operário. Porto: Afrontamento, 2005.

Fórum Social Mundial: manual de uso. Porto: Afrontamento, 2005

Renovar a teoria crítica e reinventar a emancipação social. São Paulo: Boitempo Editorial, 2007.

(Org.) Democratizar a democracia: os caminhos da democracia participativa. Rio de Janeiro: Civilização Brasileira, 2002
; FILHO, Naomar de Almeida. A universidade no século XXI. Para uma Universidade Nova. Coimbra: Edições Almedina, 2008.

; MENESES, Maria Paula (Orgs.). Epistemologias do Sul. Coimbra: Edições Almedina, 2009.

TILLY, Charles. From mobilization to revolution. Addison/ Mass: Wesley Publishing Company, 1978.

WATERMAN, Peter . O internacionalismo sindical na era de Seattle, Revista Crítica de Ciências Sociais, n, 62. Coimbra; CES, p. 33-68, 2002. 
SOCIOLOGY AND ENGAGEMENT IN THE PORTUGAL: critical reflection on labour and trade unionism in a time of crisis

\section{Elísio Estanque}

This paper aims to be an example of the critical-public sociology that is produced at CES - Centre for Social Studies of the University of Coimbra. Focusing one specific research area (sociology of work and trade unionism), the critical perspective is assumed, both in theoretical and reflective terms, as well as political praxis of the social scientist. Considering this framework, the current crisis is taken as the starting point to discuss the portuguese case on the labour issue, stressing some structural lines of the country as a European semi-periphery and showing that some of its current problems have ancient roots.

KEY-WORDS: public sociology, crisis, labour, trade unionism, Portugal.
LA SOCIOLOGIE ET L'ENGAGEMENT AU PORTUGAL: réflexions à partir du travail et du syndicalisme

\section{Elísio Estanque}

Ce paper (travail) essaie d'être un exemple de la sociologie critique publique développée par le Centre d'Etudes Sociales (CES) de l'Université de Coimbra. Le thème que l'on aborde ici (sociologie du travail et du syndicalisme) assume une perspective critique autant d'un point de vue théorique et réflexif que d'une pratique politique des sciences sociales, aspects considérés comme les deux faces d'une même médaille. Partant de ce point de vue, l'actuelle conjoncture de crise est mise en discussion et le cas portugais est analysé à la lumière de la question du travail. Certains traits structuraux du pays sont mis en évidence tel que celui de semi périphérie de l'Europe et montrent combien quelques problèmes actuels ont une origine très ancienne.

Mots-CLÉs: sociologie publique, crise, travail, syndicalisme, Portugal.

Elísio Estanque - Doutor em Sociologia pelo ISCTE. Pesquisador do CES - Centro de Estudos Sociais e Professor de Sociologia na Universidade de Coimbra. Coordenador dos Programas de Pós-Graduação em Relações de Trabalho, Desigualdades Sociais e Sindicalismo. Desenvolve pesquisas nas áreas de Sociologia do Trabalho, Classes e Desiguadades Sociais, Movimentos Sociais e Estudantis. Publicou, entre outros, Entre a Fábrica e a Comunidade (Porto, Afrontramento, 2000); Mudanças no Trabalho e Ação Sindical: Portugal, Brasil e o contexto transnacional. (Co-autor. São Paulo: Cortez, 2005; e Do Activismo à Indiferença: movimentos estudantis em Coimbra (em co-autoria com Rui Bebiano, Lisboa, Ed. ICS, 2007). 